\title{
Intravaginal isonicotinic acid hydrazide (INH) versus misoprostol for cervical ripening prior to hysteroscopy
}

\author{
Ladan Haghighi, MD' ${ }^{1}$ Zahra Najmi, MD², Samaneh Rokhgireh, MD³ ${ }^{3}$ Yousef Moradi, PhD Candidate ${ }^{4}$ \\ Department of Obstetrics and Gynecology, ${ }^{1}$ Iran University of Medical Sciences, Tehran, ${ }^{2}$ Zanjan University of Medical Sciences, Zanjan; ${ }^{3}$ Endometriosis \\ Research Center,' Iran University of Medical Sciences, Tehran; ${ }^{4}$ Department of Epidemiology, School of Public Health, Iran University of Medical \\ Sciences, Tehran, Iran
}

\section{Objective}

The aim of the present study was to compare the efficacy of vaginal isoniazid (isonicotinic acid hydrazide [INH]) and vaginal misoprostol in cervical ripening before hysteroscopic surgery.

\section{Methods}

This randomized controlled trial included patients scheduled for hysteroscopic surgery during April 2016 and June 2017. The inclusion criteria were as follows: postmenopausal women or those at premenopausal age who had not had a vaginal delivery and candidate for diagnostic or operative hysteroscopy with closed cervix before intervention. The INH group (intervention group) received $900 \mathrm{mg}$ of vaginal isoniazid (three 300-mg pills) 6-8 hours before hysteroscopic surgery. The misoprostol group (control group) received 400 micrograms of vaginal misoprostol 6-8 hours before hysteroscopic surgery. Finally, the efficacy of the 2 agents was comparatively analyzed.

\section{Results}

Baseline characteristics were comparable between the groups. In 67 cases in the INH group (95\%) and 45 in the misoprostol group (50\%), hysteroscopic entry was successful without additional mechanical dilation, and this difference was statistically significant $(P=0.001)$. The odds ratio $(O R)$ obtained in this study was 0.57 for both INH and misoprostol groups (OR, 0.57; 95\% confidence interval, 0.43-0.75). Further, 19 cases in the INH group vs. 45 cases in the misoprostol group did not respond to the intervention, indicating statistically significance $(P=0.001)$.

\section{Conclusion}

Vaginal INH is more effective than misoprostol in cervical ripening before hysteroscopic surgery and can be a good alternative to misoprostol.

Trial Registration

Iranian Registry Clinical Trial (IRCT) Identifier: IRCT2015112821506N4

Keywords: Isonicotinic acid hydrazide; Misoprostol; Cervical ripening

\section{Introduction}

Since the advent of hysteroscopic surgery, anomalies of the uterine cavity such as endometrial polyps, sub-mucosal myomas, adhesions, and uterine septums are being effectively treated [1]. Diagnostic hysteroscopy is a standard method of diagnosing intrauterine lesions, which it makes possible to carry out biopsy and intraoperative lesion removal. The sensitivity of this method has been reported to range between $84 \%$ and $97 \%$, and its specificity is between $88 \%$ and $93 \%$ [2-4]. Furthermore, hysteroscopic surgery reduces the need
Received: 2019.09.13. Revised: 2020.02.01. Accepted: 2020.03.16. Corresponding author: Yousef Moradi, PhD Candidate Department of Epidemiology, School of Public Health, Iran University of Medical Sciences, Shahid Hemmat Highway, Tehran 1449614535, Iran

E-mail: yousefmoradi211@yahoo.com https://orcid.org/0000-0002-2936-5930

Articles published in Obstet Gynecol Sci are open-access, distributed under the terms of the Creative Commons Attribution Non-Commercial License (http://creativecommons. org/licenses/by-nc/3.0/) which permits unrestricted non-commercial use, distribution, and reproduction in any medium, provided the original work is properly cited.

Copyright $\odot 2020$ Korean Society of Obstetrics and Gynecology 


\section{Obstetrics \& Gynecology Science}

Ladan Haghighi, et al. INH for cervical ripening prior to hysteroscopy

for major and unnecessary surgeries [5].

One of the major problems of hysteroscopic surgery is the difficulty in inserting a hysteroscope (especially a resectoscope) into the cervical canal [5]. Nearly half of the complications of hysteroscopic surgeries occur during entry into the cervix, such as cervical rupture, false path, and perforation of the uterus [6].

In the past, the role of laminaria and prostaglandins of the E-series in cervical dilatation and reducing intraoperative complications of cervical dilatation have been proven [7]. Misoprostol is a synthetic analogue of prostaglandin E1 used to treat and prevent gastric ulcers, which is now widely used in obstetrics and gynecology. Its applications in obstetrics and gynecology include medical abortion in the first and second trimesters of pregnancy, preparation of the cervix before vacuum aspiration or dilatation and curettage, labor induction, and prevention and treatment of postpartum hemorrhage [8-10]. Although misoprostol was manufactured for oral administration, numerous pharmacokinetic studies have shown that its active metabolite concentration is retained for longer in vaginal administration than oral [11]. The advantage of misoprostol to other prostaglandin analogues is that it is cheap, stable at room temperature, and available in the form of oral pills $[4,12]$. However, in our country, misoprostol is not always available due to its abortifacient action, which makes it the only agent for illegal medical abortion, prohibited by the government of Iran. Besides, its administration is restricted to inpatients. Therefore, finding an effective agent that can be used in the outpatient setting is seen as a priority in our country.

Isonicotinic acid hydrazide (INH) is an anti-tuberculosis agent, recently introduced for cervical ripening. It has been studied in term pregnancies, where it was as effective as misoprostol [13]. There is some evidence that the effect of $\mathrm{INH}$ on cervical ripening may be partially due to nitric oxide (NO) production in the cervix. It has previously been shown that injection of INH causes a significant increase in the NO levels in the red blood cells (RBCs) of rats, and it has been suggested that NO plays an important role in the pathogenesis of INH-induced oxidative stress in RBCs [14].

As the knowledge and data on the efficacy of this new agent on cervical ripening is still limited, especially regarding some adverse effects such as abdominal cramps, nausea, and vomiting, and because of the feasibility of using $\mathrm{INH}$ in the outpatient setting, we conducted the present study to assess the effect of vaginal INH on cervical ripening before hysteroscopic surgery and to compare the efficacy of this agent with that of misoprostol.

\section{Materials and methods}

This study was a prospective randomized controlled trial that included patients with intrauterine pathology referred to Hazrat e Rasoul e Akram Hospital, Tehran, who were candidates for hysteroscopic surgery between April 2016 and June 2017. Their medical, gynecologic, and obstetric histories were obtained one day before surgery.

The inclusion criteria were as follows: postmenopausal women or those at premenopausal age who had not had a vaginal delivery and candidate for diagnostic or operative hysteroscopy with closed internal os before intervention (no entrance of Hegar size 2). Patients were excluded if contraindications for receiving prostaglandins, such as severe asthma, glaucoma, heart disease, hypertension, or renal failure were present; severe utero-vaginal prolapse that interfered with the insertion of pills in the posterior vaginal fornix; history of cervical surgery or cervical insufficiency; simultaneous laparoscopy; and cervical myomas.

The participants were randomly assigned to 2 groups by means of computer-generated randomization, and sealed opaque medication packets were used consecutively. In order to prevent information bias, the patients and the surgeons who performed the hysteroscopic procedure were blinded to the treatment and the intervention.

The misoprostol group $(n=90)$ received 400 micrograms of vaginal misoprostol (two 200-mg pills) (Cytotec, Searle Pharmaceuticals, Sutton, UK) 6-8 hours before hysteroscopy. The INH group ( $n=86$ ) received $900 \mathrm{mg}$ of vaginal INH (three 300-mg pills) (Daru Pakhsh, Tehran, Iran) 6-8 hours before hysteroscopy. The tablets were administered by one of the research team members after complete vaginal examination. Prior to general anesthesia, the patients were asked about adverse drug reactions such as nausea and vomiting, vaginal bleeding, diarrhea, and uterine cramps, and a questionnaire was filled out by the surgeon.

The surgeries were carried out on all the patients by one surgeon. The hysteroscopic surgeries were performed using a BETTOCCHI Hysteroscope ( $5 \mathrm{~mm}$ ) based on a 2.9- $\mathrm{mm}$ rodlens telescope with a 30-degree lens angle from KARL STORZ 


\section{Obstetrics \& Gynecology Science}

Vol. 63, No. 4, 2020

(Tuttlingen, Germany). The primary outcome measure was hysteroscope entry with no force or mechanical dilation. Interventions were considered as no-response if we needed to perform mechanical dilation before hysteroscope entry. Secondary outcomes were as follows: non-responsive patients, maximum Hegar size in non-responsive patients, intrauterine pathology, side effects of cervical dilatation (bleeding, false path, uterine perforation, and cervical rupture), and adverse drug reactions before surgery. The outcome measures were compared between the misoprostol and INH groups using SPSS statistical tests.

\section{Main outcome}

The main outcome in this study was hysteroscope entry with no force or mechanical dilation.

\section{Sample size}

The sample size for this study was calculated according to previous studies [15]. The statistical power and significance level were $80 \%$ and $5 \%$, respectively. Although 52 participants in each group was the computed result, to increase the power, 176 patients (90 patients in the misoprostol group and 86 in INH group) were enrolled in the study (Fig. 1) [16-19].

\section{Statistical analysis}

Statistical analysis was performed using SPSS software, version 16 (SPSS Inc., Chicago, IL, USA). Data were presented as the mean \pm standard deviations for quantitative variables and compared using the $t$-test. Independent nominal data were analyzed using the $\chi^{2}$ test and were reported as percentages. Furthermore, logistic regression was used to obtain the odds ratio $(\mathrm{OR})$ and hazard prediction. The significance level in this study was set at $P<0.05$.

\section{Results}

The age, height, and weight of the women in the INH group and misoprostol group were comparable $(38.59 \pm 10.57$ vs. $40.42 \pm 10.81$ years, $160.62 \pm 5.91$ vs. $161.97 \pm 7.08 \mathrm{~cm}$ and $72.1 \pm 14.52$ vs. $72.73 \pm 8.22 \mathrm{~kg}$ ) ( $P>0.05)$. The body mass index of the INH group was approximately equal to that of the misoprostol group $(27.79 \pm 3.29$ vs. $27.98 \pm 5.58)$. Gravidity of the women in the INH and misoprostol groups was $1.39 \pm 0.49$ and $1.27 \pm 0.44$, respectively; the difference was not statistically significant $(P=0.087)$ (Table 1$)$.

Table 1 shows the comparison of the qualitative variables

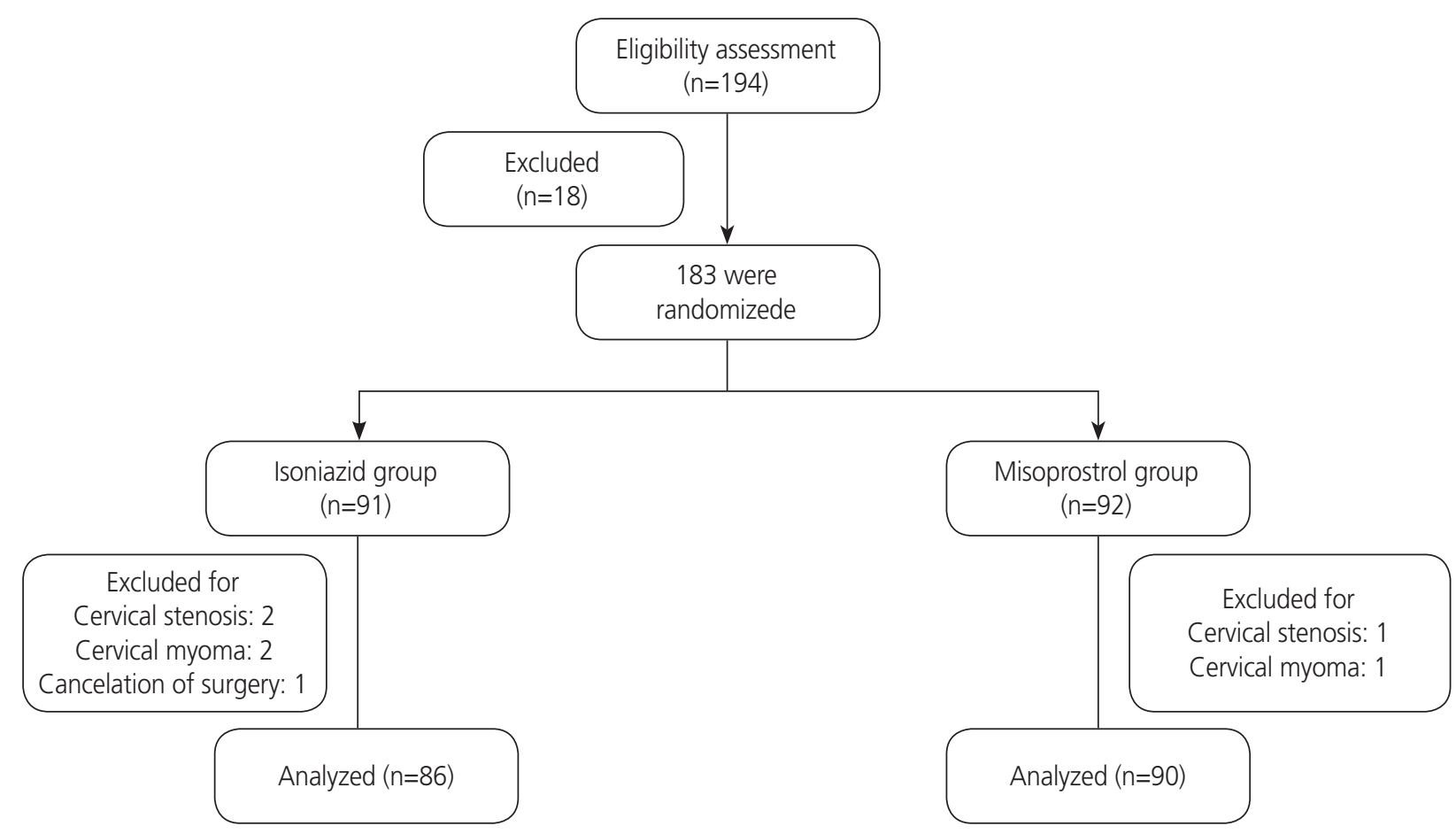

Fig. 1. CONSORT diagram of the trial. 


\section{Obstetrics \& Gynecology Science}

Ladan Haghighi, et al. INH for cervical ripening prior to hysteroscopy

between the misoprostol and INH groups. As can be seen, in 45 patients in the misoprostol group (50\%) and 67 in the INH group (95\%), hysteroscope entry was successful without additional mechanical dilation, and this difference was statistically significant $(P=0.001)$ (Table 2 ).

The OR obtained in this study was 0.57 for both misoprostol and INH groups, indicating that the likelihood of hysteroscope entry without additional mechanical dilation was $43 \%$ lower in the misoprostol group than in the INH group (OR, 0.57 ; 95\% confidence interval [Cl], 0.43-0.75) (Table 2 and Fig. 2).

Further, the OR of non-response in the misoprostol group was 1.75 times that in the INH recipients, meaning 75\% higher (OR, 1.75; 95\% Cl, 1.32-2.30) (Table 2). Comparison of intrauterine pathology between the 2 groups showed that the numbers of women with Asherman's syndrome in the misoprostol group and INH group were 4 (4.4\%) and 0 $(0 \%)$, respectively, while 12 women $(13.3 \%)$ in the misoprostol group and $19(22.1 \%)$ in the INH group had no notable intrauterine pathology, and this difference was statistically significant $(P=0.001)$.

We did not encounter any adverse drug reactions in either group. However, we had one case of false path in INH group and one case of uterine perforation during hysteroscope entry in a very anteverted uterus in the misoprostol group; both were diagnosed and managed properly.

\section{Discussion}

The results of the present study show that INH is more effective than misoprostol in cervical ripening before hysteroscopic surgery. The aim of this randomized clinical trial was to compare the efficacy of vaginal misoprostol and INH on cervical ripening before hysteroscopy. There have been numerous studies on the effect of misoprostol on cervical preparation before hysteroscopy, but none have compared it with INH.

For example, in a study by Batukan et al. [11], the effect of

Table 1. Basic demographic factors in 2 groups

\begin{tabular}{lcccc}
\hline Variables & INH (n=86) & Misoprostol (n=90) & P-value & $\begin{array}{c}\text { OR (95\% Cl) } \\
\text { (misoprostol/INH) }\end{array}$ \\
\hline Age & $38.59 \pm 10.57$ & $40.42 \pm 10.81$ & 0.258 & - \\
BMI & $27.98 \pm 5.58$ & $27.79 \pm 3.29$ & 0.647 & - \\
Gravidity & $1.27 \pm 0.44$ & $1.39 \pm 0.49$ & 0.087 & - \\
Parity & & & & \\
No delivery & $6(31.6)$ & $10(22.2)$ & 0.786 & 1.00 \\
1 delivery & $3(15.8)$ & $13(28.9)$ & 0.143 & $0.53(0.23-1.23)$ \\
2 delivery & $7(36.8)$ & $9(20.0)$ & 0.582 & $0.78(0.33-1.83)$ \\
3 and more delivery & $3(15.8)$ & $13(28.9)$ & 0.195 & $0.54(0.22-1.27)$ \\
Menshis & & & & \\
Regular & $25(29.1)$ & $20(22.2)$ & 0.251 & 1.00 \\
Menorrhagia & $3(3.5)$ & $5(5.6)$ & 0.288 & $0.48(0.10-2.25)$ \\
Metrorrhagia & $19(22.1)$ & $22(24.4)$ & 0.262 & $0.69(0.29-1.61)$ \\
Menometrorrhagia & $14(16.3)$ & $20(22.2)$ & 0.150 & $0.56(0.22-1.37)$ \\
Oligomenorrhea & $3(3.5)$ & $1(1.1)$ & 0.421 & $2.40(0.23-24.87)$ \\
Amenorrhea & $1(1.2)$ & $1(1.1)$ & 0.699 & $0.80(0.04-13.06)$ \\
Irregular & $21(24.4)$ & $21(23.3)$ & 0.381 & $0.80(0.34-1.86)$ \\
Menopause & & & & \\
Yes & $12(14)$ & $82(9.91 .1)$ & - & 1.00 \\
No & $74(86)$ & 0.613 & $1.05(0.94-1.17)$ \\
\hline
\end{tabular}

Values are presented as mean \pm standard deviation or number (\%).

$\mathrm{BMI}$, body mass index; $\mathrm{Cl}$, confidence interval; $\mathrm{OR}$, odds ratio; INH, isonicotinic acid hydrazide. 


\section{Obstetrics \& Gynecology Science}

Vol. 63, No. 4, 2020

Table 2. Outcome variables in 2 groups and predict of variables by logistic regression

\begin{tabular}{|c|c|c|c|c|}
\hline Variables & INH $(n=86)$ & Misoprostol $(n=90)$ & $P$-value & $\begin{array}{c}\text { OR }(95 \% \mathrm{Cl}) \\
\text { (misoprostol/INH) }\end{array}$ \\
\hline \multicolumn{5}{|l|}{ Primary outcomes } \\
\hline \multicolumn{5}{|l|}{ Hysteroscopy entrance } \\
\hline Yes & $67(77.9)$ & $45(50.0)$ & 1.000 & 1.00 \\
\hline No & $19(22.1)$ & $45(50.0)$ & 0.0001 & $0.57(0.43-0.75)$ \\
\hline \multicolumn{5}{|l|}{ Secondary outcomes } \\
\hline \multicolumn{5}{|l|}{ Non responses } \\
\hline Yes & $19(22.1)$ & $45(50.0)$ & 1.000 & 1.00 \\
\hline No & 67 (77.9) & $45(50.0)$ & 0.0001 & $1.75(1.32-2.30)$ \\
\hline \multicolumn{5}{|l|}{ Intra uterine pathology } \\
\hline Normal & $19(22.1)$ & $12(13.3)$ & - & 1.00 \\
\hline Polyp & $31(36.0)$ & $42(46.7)$ & 0.090 & $0.71(0.26-1.95)$ \\
\hline Myoma & $17(19.8)$ & $15(16.7)$ & 0.513 & $0.75(0.56-0.99)$ \\
\hline Asherman's syndrome & $0(0)$ & $4(4.4)$ & 0.035 & $0.94(0.22-0.99)$ \\
\hline Septum & $6(7.0)$ & $4(4.4)$ & 0.612 & $0.63(0.07-5.10)$ \\
\hline Atrophy & $2(2.0)$ & $2(2.2)$ & 0.530 & $0.90(0.27-3.01)$ \\
\hline Focal hyperplasia & $10(11.6)$ & $7(7.8)$ & 0.554 & $1.05(0.95-1.16)$ \\
\hline Product of conception & $1(1.2)$ & $4(4.4)$ & 0.035 & $0.75(0.56-0.99)$ \\
\hline Max Hegar size in nonresponses & $3.73 \pm 1.28$ & $3.84 \pm 1.04$ & 0.726 & - \\
\hline
\end{tabular}

Values are presented as number (\%) or mean \pm standard deviation.

$\mathrm{Cl}$, confidence interval; OR, odds ratio; INH, isonicotinic acid hydrazide.

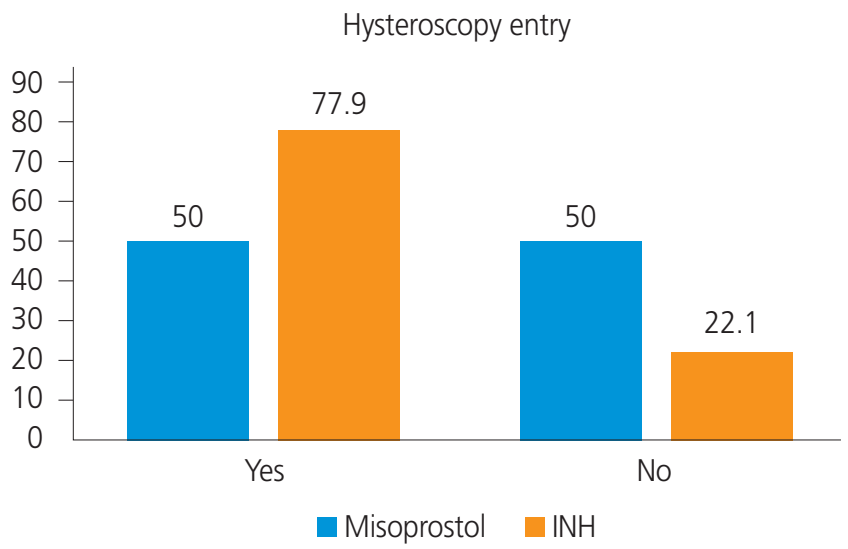

Fig. 2. The compare of frequency of hysteroscopy entry without mechanical dilation in 2 group. INH, isonicotinic acid hydrazide.

vaginal and oral misoprostol on cervical preparation before hysteroscopy was evaluated, and the results showed that oral administration of misoprostol was preferable to vaginal administration.

In the present study, the hysteroscope entered the uterus with no additional mechanical dilatation in $50 \%$ and $77.9 \%$ of the women in the misoprostol group and INH group, respectively. Moreover, the likelihood of hysteroscope entry was $43 \%$ lower in the misoprostol group than in the INH group. On the other hand, the OR of non-response in the misoprostol group was $75 \%$ higher than that in the INH group. The ORs show that the incidence of Asherman's syndrome in the misoprostol group was 0.94 times that in the vaginal INH group.

$\mathrm{INH}$ is a recently introduced agent for cervical ripening. The results of a study, conducted by Haghighi and Mohabatian [13] showed that vaginal INH is an effective agent for cervical ripening prior to labor induction in term pregnancies. The mechanism of action of INH on cervical dilatation is similar to that of NO donors. The results of some studies showed that INH affects cervical dilatation via production of NO [14]. ElKhayat et al. [20] showed that primary cervical dilatation and the duration of dilatation were higher with vaginal misoprostol than with Foley catheter plus vaginal isosorbide mononitrate, but there was no significant difference between the 


\section{Obstetrics \& Gynecology Science}

Ladan Haghighi, et al. INH for cervical ripening prior to hysteroscopy

2 groups in terms of the duration of surgery or difficult in dilatation. The lack of a statistically significant difference in their study might be due to different sample sizes or methods from those used in the present study. On the other hand, Waddell et al. [21] found that the use of vaginal misoprostol before hysteroscopy reduced the pain during and pressure required for cervical dilatation.

The results of numerous studies on the effect of misoprostol on cervical dilatation have shown that using vaginal misoprostol had a more pronounced effect on cervical dilatation than its sublingual form. Bisharah et al. [22] randomly assigned 40 women to an intervention group (100 mg of sublingual misoprostol) and a placebo group and found no significant difference between the 2 groups in terms of uterine dilatation. The results of a study by Mulayim et al. [23] showed that cervical dilatation time was longer in the control (placebo) group than in the intervention (sublingual misoprostol use) group; thus, cervical tearing was greater in the control group. In a study conducted by Preutthipan and Herabutya [24], vaginal misoprostol was found to reduce dilatation time in premenopausal women. Another study by Sordia-Hernández et al. [25] showed that the time of hysteroscopic surgery in the vaginal misoprostol group was significantly shorter than that in the placebo and sublingual misoprostol groups.

The strength of this study is that it compares the effect of vaginal misoprostol with that of other vaginal medications. In many studies, vaginal misoprostol groups have been compared with placebo groups or rectal, oral, or sublingual misoprostol administration. This method made it possible to compare the effect of 2 different drugs on vaginal dilatation.

A study conducted by Inal et al. [26] showed that dinoprostone had a greater effect on cervical dilatation than misoprostol. In the present study, the OR obtained for hysteroscopic entrance in the misoprostol and INH groups was 0.57 (0.430.75), which indicated that the likelihood of hysteroscope entry into the uterus in the misoprostol group was $43 \%$ lower than that of the INH group. This means that cervical dilatation in the women receiving misoprostol was less than in the $\mathrm{INH}$ recipients.

INH can be simply used as a ripening agent before hysteroscopy. It is easily available and does not seem to have any complications. However, its underlying mechanism of cervical ripening is unknown. Our study was limited by its small sample size. Further research is needed to determine the mechanisms of action and clinical efficacy of INH against that of other ripening agents to find the best dosage and timing of INH for ripening of cervix before hysteroscopy.

In conclusion, vaginal INH seems to be more effective than misoprostol in cervical ripening before hysteroscopic surgery and can be a good alternative to misoprostol.

\section{Conflict of interest}

No potential conflict of interest relevant to this article was reported.

\section{Acknowledgements}

This paper is derived from a medical doctorate thesis of Iran Medical Sciences University.

\section{Ethical approval}

The study was approved by the Local Ethics Committee of Iran University of Medical Sciences, Tehran, Iran and registered in the Iranian Registry of Clinical Trials (IRCT.ir); ID number: IRCT2015112821506N4.

\section{Patient consent}

In this study, informed consent was received from all the participants and their partners.

\section{References}

1. Dogru A, Sargin F, Celik M, Sagiroglu AE, Goksel MM, Sayhan $\mathrm{H}$. The rate of device-associated nosocomial infections in a medical surgical intensive care unit of a training and research hospital in Turkey: one-year outcomes. Jpn J Infect Dis 2010;63:95-8.

2. Eggimann P, Sax H, Pittet D. Catheter-related infections. Microbes Infect 2004;6:1033-42.

3. Randolph JF Jr, Ying YK, Maier DB, Schmidt CL, Riddick $\mathrm{DH}$. Comparison of real-time ultrasonography, hystero- 


\section{Obstetrics \& Gynecology Science}

Vol. 63, No. 4, 2020

salpingography, and laparoscopy/hysteroscopy in the evaluation of uterine abnormalities and tubal patency. Fertil Steril 1986;46:828-32.

4. Wolman I, Jaffa AJ, Hartoov J, Bar-Am A, David MP. Sensitivity and specificity of sonohysterography for the evaluation of the uterine cavity in perimenopausal patients. J Ultrasound Med 1996;15:285-8.

5. Munro MG, Jensen J, Purdon TF. Narrow caliber office hysteroscope. J Am Assoc Gynecol Laparosc 1994;1:S24.

6. Campo R, Van Belle Y, Rombauts L, Brosens I, Gordts S. Office mini-hysteroscopy. Hum Reprod Update 1999;5:73-81.

7. Dingfelder JR, Brenner WE, Hendricks CH, Staurovsky LG. Reduction of cervical resistance by prostaglandin suppositories prior to dilatation for induced abortion. Am J Obstet Gynecol 1975;122:25-30.

8. Christensen NJ, Bygdeman M, Gréen K. Comparison of different prostaglandin analogues and laminaria for preoperative dilatation of the cervix in late first trimester abortion. Contraception 1983;27:51-61.

9. Jain JK, Mishell DR Jr. A comparison of misoprostol with and without laminaria tents for induction of secondtrimester abortion. Am J Obstet Gynecol 1996;175:1737.

10. Ngai SW, Yeung KC, Lao T, Ho PC. Oral misoprostol versus vaginal gemeprost for cervical dilatation prior to vacuum aspiration in women in the sixth to twelfth week of gestation. Contraception 1995;51:347-50.

11. Batukan C, Ozgun MT, Ozcelik B, Aygen E, Sahin Y, Turkyilmaz C. Cervical ripening before operative hysteroscopy in premenopausal women: a randomized, double-blind, placebo-controlled comparison of vaginal and oral misoprostol. Fertil Steril 2008;89:966-73.

12. Siddique S, Howlader MJ, Saha J, Begum KS. A comparison of orally administered misoprostol with vaginally administered misoprostol for cervical ripening and labour induction. KYAMC Journal 2017;7:668-72.

13. Haghighi L, Mohabatian B. Isonicotinic acid hydrazide (INH): a new agent for cervical ripening at term. J Obstet Gynaecol 2015;35:251-4.

14. Yilmaz HR, Uz E, Gökalp O, Ozçelik N, Ciçek E, Özer MK. Protective role of caffeic acid phenethyl ester and erdosteine on activities of purine-catabolizing enzymes and level of nitric oxide in red blood cells of isoniazidadministered rats. Toxicol Ind Health 2008;24:519-24.
15. Haghighi L, Homam H, Raoofi Z, Najmi Z. Intravaginal isosorbide dinitrate or misoprostol for cervical ripening prior to induction of labour: a randomised controlled trial. J Obstet Gynaecol 2013;33:272-6.

16. Machin D, Campbell MJ, Tan SB, Tan SH. Sample size tables for clinical studies. Hoboken (NJ): John Wiley \& Sons; 2011.

17. Sokal RR, Jamesrohlf F. Introduction to biostatistics. 2nd ed. New York (NY): W. H. Freeman and Company; 2009.

18. Zar JH. Biostatistical analysis. Delhi: Pearson Education, India; 1999.

19. Abotorabi S, Mohammadi M, Bagherivand S, Oveisi S. A pilot randomized controlled trial to evaluate isosorbide mononitrate (IMN) efficiency for cervical ripening prior to labor induction in Iranian pregnant women. Iran J Pharm Res 2019;18:988-94.

20. El-Khayat W, Alelaiw H, El-kateb A, Elsemary A. Comparing vaginal misoprostol versus Foley catheter plus vaginal isosorbide mononitrate for labor induction. J Matern Fetal Neonatal Med 2016;29:487-92.

21. Waddell G, Desindes S, Takser L, Beauchemin MC, Bessette P. Cervical ripening using vaginal misoprostol before hysteroscopy: a double-blind randomized trial. J Minim Invasive Gynecol 2008;15:739-44.

22. Bisharah M, Al-Fozan $\mathrm{H}$, Tulandi T. A randomized trial of sublingual misoprostol for cervical priming before hysteroscopy. J Am Assoc Gynecol Laparosc 2003;10:390-1.

23. Mulayim B, Celik NY, Onalan G, Bagis T, Zeyneloglu $H B$. Sublingual misoprostol for cervical ripening before diagnostic hysteroscopy in premenopausal women: a randomized, double blind, placebo-controlled trial. Fertil Steril 2010;93:2400-4.

24. Preutthipan S, Herabutya Y. Vaginal misoprostol for cervical priming before operative hysteroscopy: a randomized controlled trial. Obstet Gynecol 2000;96:890-4.

25. Sordia-Hernández LH, Rosales-Tristan E, Vazquez-Mendez J, Merino M, Iglesias JL, Garza-Leal JG, et al. Effectiveness of misoprostol for office hysteroscopy without anesthesia in infertile patients. Fertil Steril 2011;95:75961.

26. Inal HA, Ozturk Inal ZH, Tonguc E, Var T. Comparison of vaginal misoprostol and dinoprostone for cervical ripening before diagnostic hysteroscopy in nulliparous women. Fertil Steril 2015;103:1326-31. 